\title{
NEW SET UP FOR TENSILE TEST PERFORMED ON THIN BAMBOO
}

\author{
Silvia Greco ${ }^{1}$, Luisa Molari ${ }^{2}$ \\ 1 viale Risorgimento 2, 40136 Bologna, Italy, silviagreco1610@ gmail.com \\ DICAM, Alma Mater Studiorum - University of Bologna. \\ 2 viale Risorgimento 2, 40136 Bologna, Italy, luisa.molari@unibo.it \\ DICAM, Alma Mater Studiorum - University of Bologna.
}

\begin{abstract}
The tensile test is one of the most important and widespread tests on bamboo and materials in general. This test on bamboo presents some difficulties if performed according to International Standards, amplified in the case of thin bamboo.

The aim of this study is to introduce a new tensile test set up able to improve the procedure suggested by International Standards to be applicable to all bamboo species including the thinner varieties growing in the temperate climate of Europe. Materials and techniques adopted in the procedure are easy to find and to be used. Results show the effectiveness of the procedure.
\end{abstract}

Keywords: Bamboo, Mechanical properties, tensile test, Standards, Phyllostachys Viridigluacescens.

\section{INTRODUCTION}

Bamboo can have a new crucial role among future sustainable materials for constructions; it combines high mechanical resistance, low specific weight to a very high renewable capability. There are over 1500 bamboo species, growing in almost all the world, mainly in tropical, subtropical and in some temperate areas. According to the environmental conditions, there are differences between them, in terms of geometries as diameters, thickness and length between internodes, and in terms of mechanical characteristics, as tensile, compressive strength and modulus of elasticity (Liese, 2012).

The increasing interest in bamboo and the perspective to use it in different engineering contexts require standards for mechanical characterization (Harris et al 2012). To extend the use of bamboo as structural material, even where it is not traditionally used, is necessary to gain the knowledge of the mechanical characteristics used in design. For this purpose, International Organization for Standardization (ISO) developed Standards for determining the mechanical properties of bamboo in 2004 (ISO-22156, 2004), then updated in 2017 (ISO-22157, 2017).

These Standards describe the procedure for tensile test parallel to fibers, compressive test parallel and perpendicular to fibers, shear test parallel to fibers and bending test parallel and perpendicular to fibers. Compressive, shear and bending test are easy to perform and the data on strength found in literature for each species are in good accordance. On the contrary the tensile test are difficult to perform and the data reported on the same species vary considerably in different studies.

In this paper a new tensile test set up able to improve the procedure suggested by the 
Standards is presented. Materials and techniques adopted are easy to find and to be used.

\section{METHODOLOGY}

In a tensile test, the geometry of the specimen, the Gag-bits anchoring and the tool through which strain are measured are three crucial points.

Regarding the geometry of the specimen, traditional dog bone geometry of the specimen suggested by Standards (ISO-22156, 2004) is difficult to cut in bamboo. Furthermore, when testing the dog bone specimen the curvature of extremities, not negligible for little bamboo diameters can lead to failure (as shown in Figure 1). The dog bone specimen may be overcome as the updated International Standards (ISO$22157,2017)$ suggested by radially-oriented specimens having rectangular cross section with dimensions equal to the culm wall thickness and width equal to one-half of culm wall thickness or less. Specimen width should not exceed $20 \mathrm{~mm}$. For a thin bamboo culm having thickness around $6-8 \mathrm{~mm}$ the production of these specimens is very difficult.

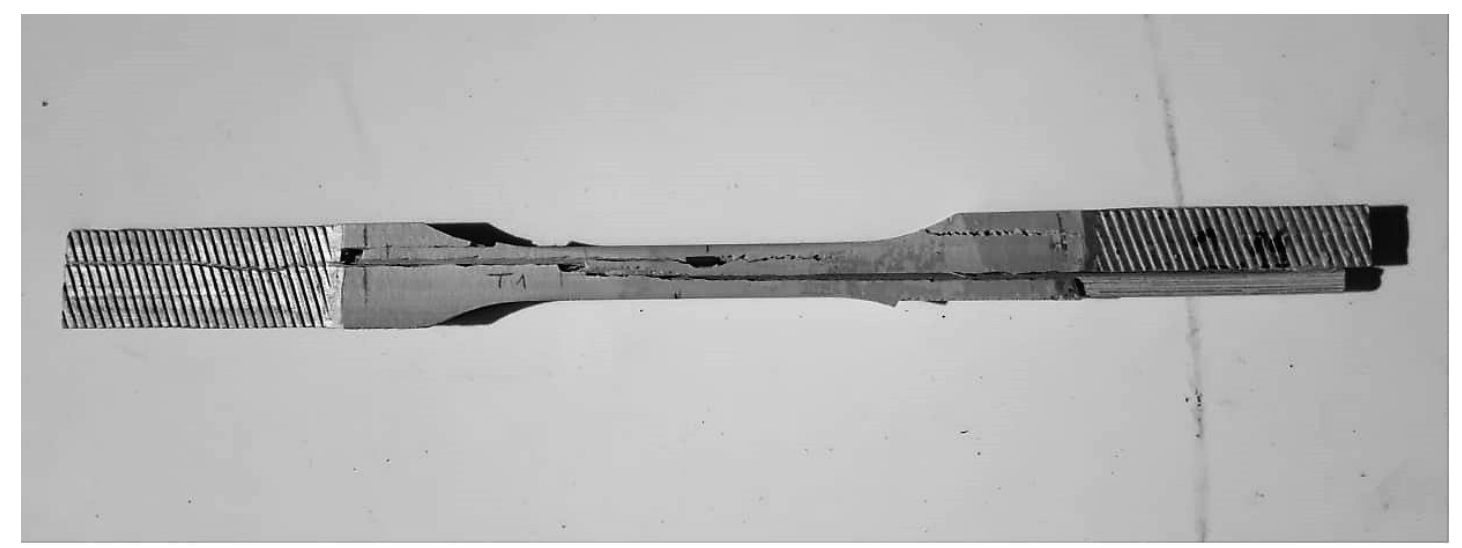

Figure 1 Dog bone specimen after rupture.

Regarding Gag-bits anchoring the international Standard suggests soft wood tabs of dimensions equal to thickness of the specimen between the specimen and the machine anchorage. During the test, the supports can slip resulting in test failure. To overcome the problem, different types of anchoring can be used. In particular, we tested two different types of reinforce glued with resin at the extremities of the specimen: two metal plates and a tubular metal support. As shown in Figure 2, in the first case the failure started from the support, while in the second case the failure occurs in the gauge portion indicating the success of the procedure.

Regarding strain measurement, the current Standard suggests to determine the modulus of elasticity $E$, through a strain measure obtained by a strain gauge posed in the middle of the length of the specimen, parallel to the loading axis or an externally mounted mechanical gauge. To understand the differences in strain measurements, the data from measurements of three different devices are compared: two local devices (a strain gauge and a mechanical deformometer ) and a measure of strain derived by the encoder system of the press machine. 


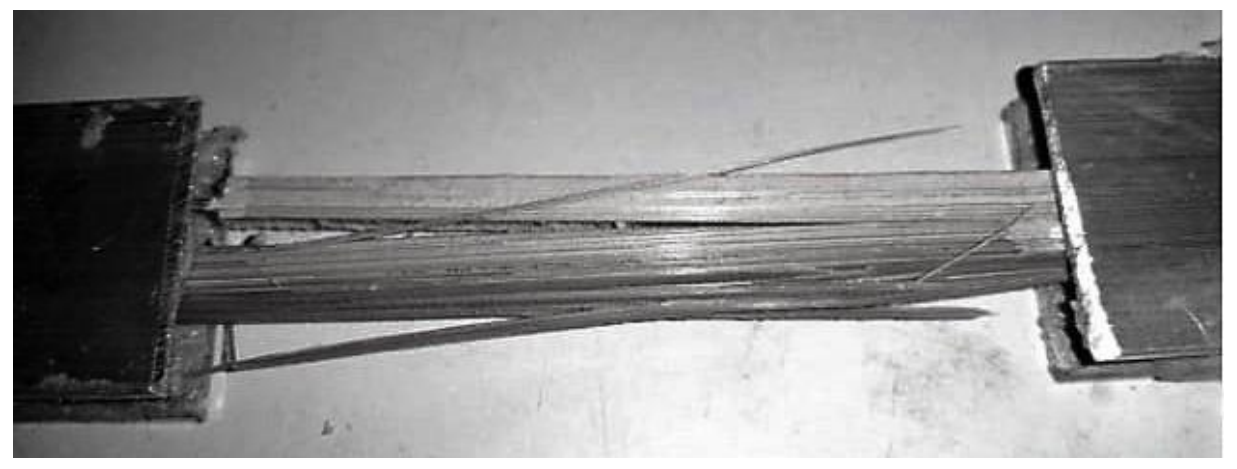

(a)

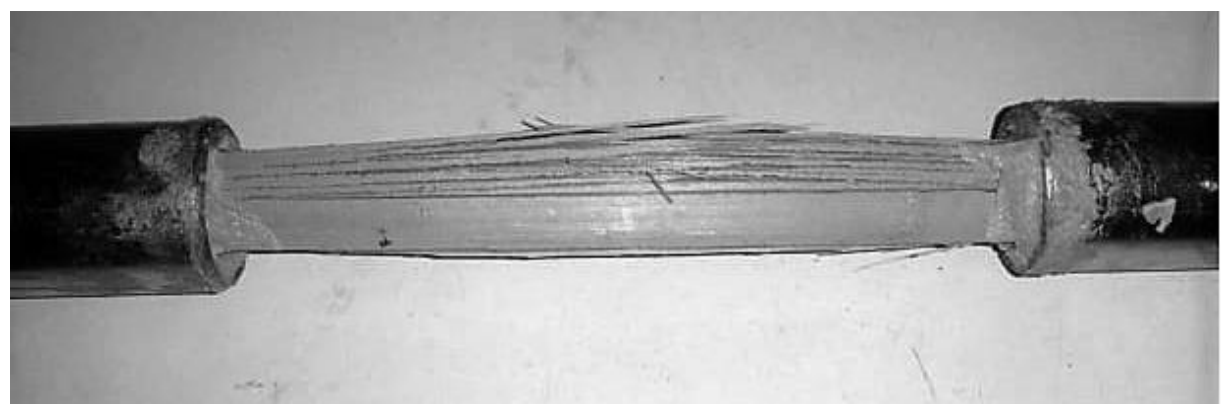

(b)

Figure 2 (a) Failure of the specimen with two metal plates, (b) failure of the specimen with tubular metal supports.

An example of strain measurements acquired by the three different devices versus the correspondent stress are shown in Figure 3. Inspecting the graph reveals that the two local devices (deformometer and strain gauge) give very close results while the strain measure derived by the endcoder signal is considerably affected by errors due to the local plastic deformation of the specimen in anchoring position and to deformation and movements of press machine. Local strain measures made with strain gauges or deformometer are mandatory to have good estimation of specimen's stiffness. 


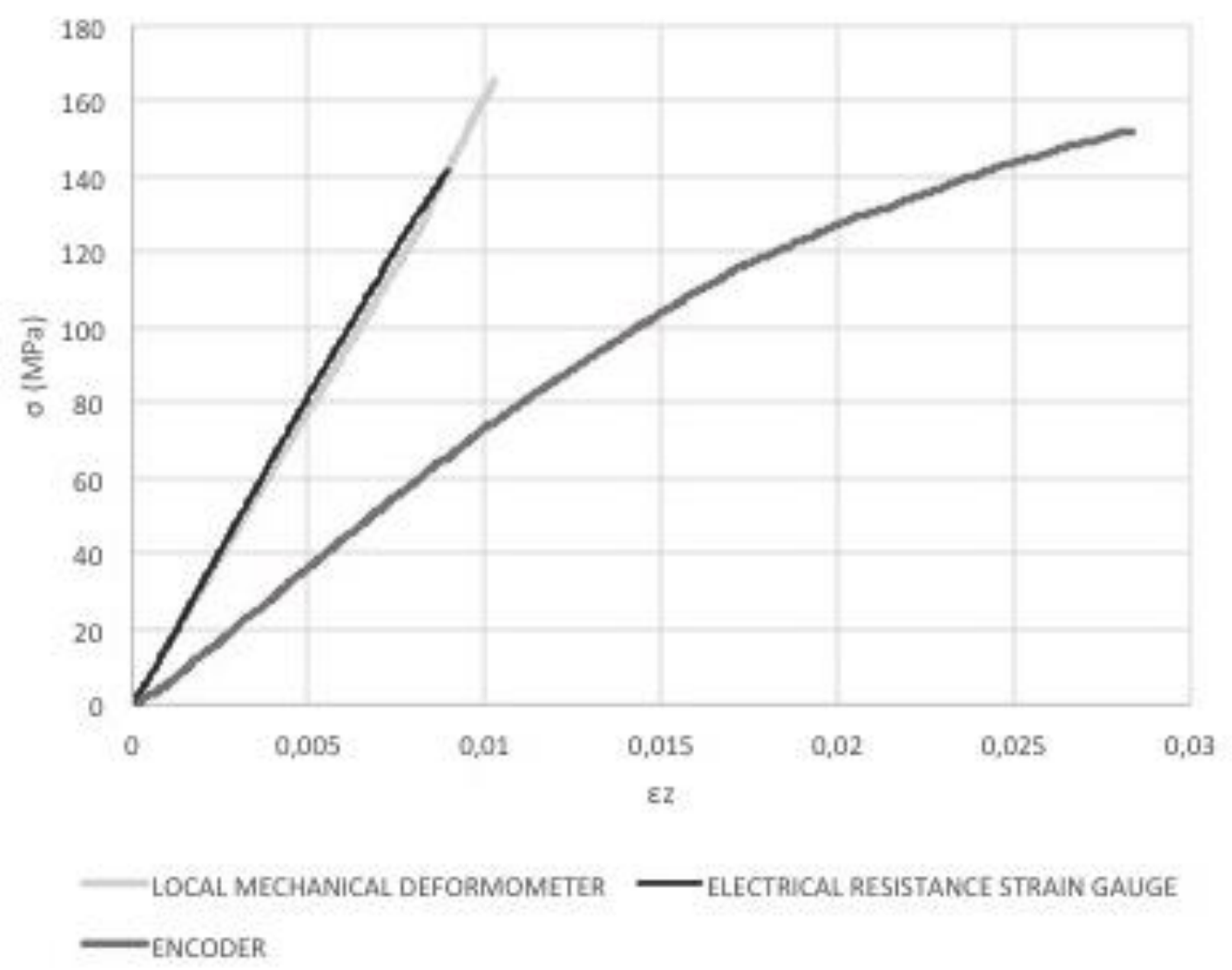

Figure 3. Comparison between local measurments device (elestrical

resistance strain gauge and mechanical deformometer) and encoder measuring.

\section{PROPOSED PROCEDURE}

A new set up is proposed for conducting the tensile test.

Regarding specimen geometry, the stick shape with a rectangular cross section is adopted, with one dimension equal to the thickness of the culm and the other one, the width, equal to half of the first dimension. In respect to the current Standards, a further requirement is introduced that the width should be not less than $4 \mathrm{~mm}$ in order to easily cut the specimen and to be able to collocate a standard strain gauge.

Regarding the specimen anchoring, it is proposed to bury the extremities of the specimen in a tubular metal support glued to the specimen with a synthetic resin. The free length of the specimen has to be between 5 and $10 \mathrm{~cm}$ as required by the Standards. We suggest the same length range for the reinforced extremities. The axially centering of the specimen in respect to the loading axis has to be accurate to avoid bending effects. To ensure the co-axiality, we suggest to interpose two circular rubber rings (two for each side) between the specimen and the tubular support (see Figure 4). We suggest to prepare the specimen with the following steps: firstly, insert the ends of the specimen in two tubular metal support with a hole on lateral surface, then interpose the rubber ring, and eventually inject the resin through the hole. It is preferable a pasty resin than a liquid one to avoid the leakage (in the following a commercial resin Sikadur $31 \mathrm{CF}$ was used).

The strain of the specimen is measured by a strain gauge or a deformometer posed in the middle of the specimen in the outer part of the culm. 


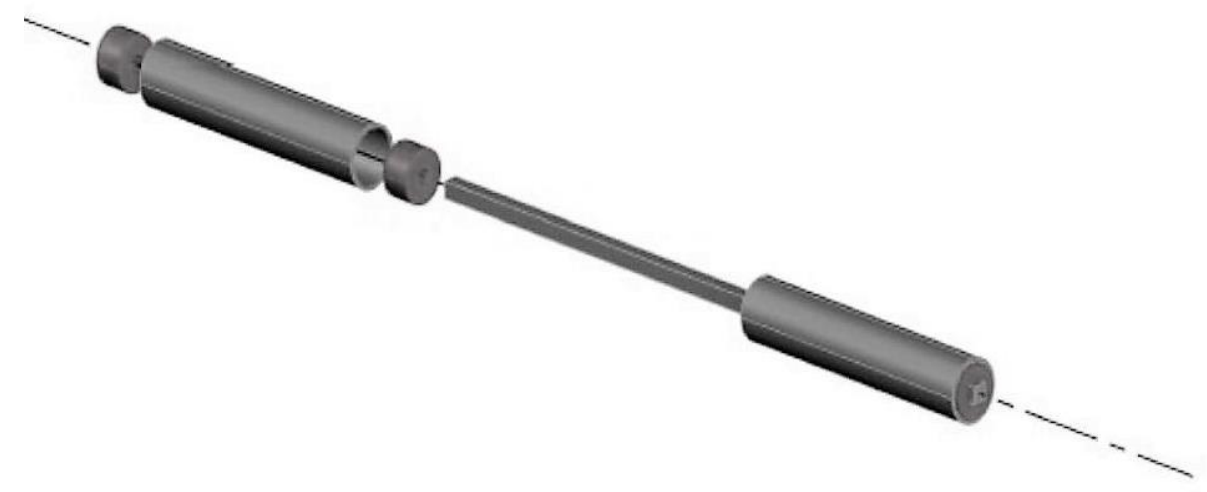

Figure 4. Proposed set up

\section{RESULTS}

The effectiveness of the proposed procedure is validated in an experimental campaign carried on Phyllostachys Viridi-glaucescens bamboo grown in the central part of Italy. The geometry of the tested culms has an average wall thickness of $5.5 \mathrm{~mm}$. The tensile strength and the Young modulus for all the specimens are reported by Greco et al. (2019), where the full mechanical characterization of Phyllostachys Viridiglaucescens is presented.

Specimens with and without nodes are tested (6 with node and 6 without node). A mean value of $234.64 \mathrm{MPa}$ for tensile strength with a standard deviation of $35.62 \mathrm{MPa}$ is obtained in the case without node and $200.32 \mathrm{MPa}$ with a standard deviation of 26.57 $\mathrm{MPa}$ in the case with node.

The mean value of the strength over all the specimens is $216.5 \mathrm{MPa}$, with a standard deviation of $35.4 \mathrm{MPa}$. A mean value of $18 \mathrm{GPa}$ for Young modulus with a standard deviation of $1.81 \mathrm{GPa}$ is obtained for the case without node and a mean value of 19.39 GPa with a standard deviation of $3.46 \mathrm{GPa}$ for the case with the node. The mean value over all the specimens was $18.8 \mathrm{GPa}$ with a standard deviation equal to $2.86 \mathrm{GPa}$. For all the specimens the main value of moisture content equal to $9.517 \%$ is measured according to the procedure suggested in the current Standards.

The standard deviation is $161 \%$ of the mean value for the strength $(15 \backslash \%$ in the case of specimens without node and $131 \%$ in the case of specimens with node). Also regarding the Young modulus the standard deviation is $161 \%$ of the mean value $(101 \%$ for the tests without node and $181 \%$ for the tests with node).

For all the specimens a brittle failure due to the failure of the fibers occurs in the middle of the specimen as represented in Fig. 5 and it is not influenced by the gag-bits anchoring.

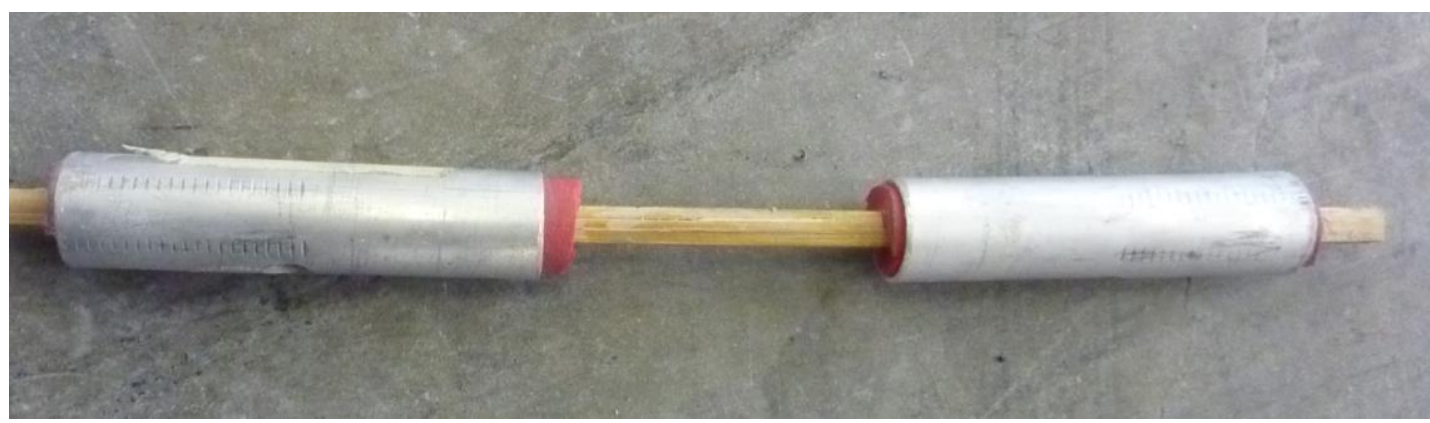




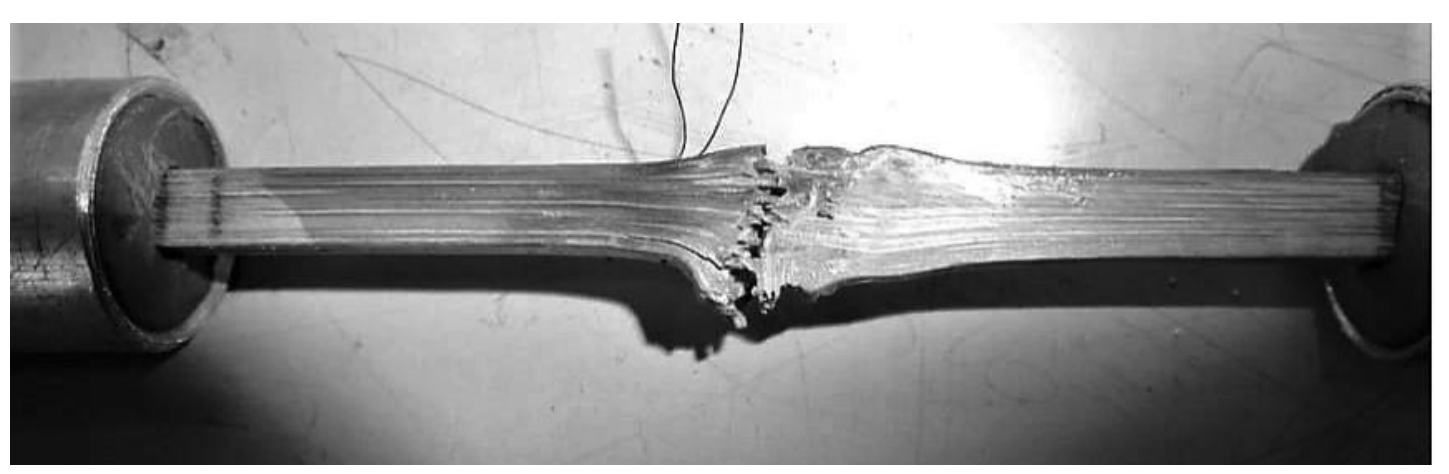

Figure 5. Tensile test parallel to the fibers: deformed specimen without and with node

\section{CONCLUSIONS}

In a perspective of sustainability, it is advantageous to know the characteristics of bamboo coming from the country in which it will be used. It is therefore crucial that International Standards adopt procedures valid for all the situations. The procedure recommended in the Standards are hard to follow in case of thin bamboo as those grown in temperate climate. A discussion on the critical points of the actual Standards has been proposed and a new procedure for conducting tensile test has been suggested. The effectiveness of the proposed procedure has been illustrated through an experimental campaign conducted on Phyllostachys Viridiglaucescens grown in Italy.

\section{REFERENCES}

Greco S., Molari L., Maraldi M. (2019) Assessing the mechanical properties of bamboo cultivated in Italy, $18^{\text {th }}$ International Congress on Non-Conventional Material and Technologies, NOCMAT, 24-26 July 2019, Nairobi, Kenya.

Harries K.A., Sharma B., Richard M. (2012) Structural Use of Full Culm Bamboo: The Path to Standardization, International J. Arch. Engng Constr. Vol 1, No 2, 6675 .

ISO 22156, Bamboo Structural design, International Standard, (2004).

ISO 22157-1, Bamboo structures: Determination of physical and mechanical properties of bamboo culms, International Standard, (2017)

Liese M. (2012) Bamboo The Plant and its Uses, Springer. 
